\title{
FPGA based gate signal generator for three-level neutral point clamped inverters
}

Link to publication record in Manchester Research Explorer

\section{Citation for published version (APA):}

Ahmed, M. R., \& Rogers, D. J. (2015). FPGA based gate signal generator for three-level neutral point clamped inverters. In host publication IEEE.

\section{Published in:}

host publication

\section{Citing this paper}

Please note that where the full-text provided on Manchester Research Explorer is the Author Accepted Manuscript or Proof version this may differ from the final Published version. If citing, it is advised that you check and use the publisher's definitive version.

\section{General rights}

Copyright and moral rights for the publications made accessible in the Research Explorer are retained by the authors and/or other copyright owners and it is a condition of accessing publications that users recognise and abide by the legal requirements associated with these rights.

\section{Takedown policy}

If you believe that this document breaches copyright please refer to the University of Manchester's Takedown Procedures [http://man.ac.uk/04Y6Bo] or contact uml.scholarlycommunications@manchester.ac.uk providing relevant details, so we can investigate your claim.

\section{OPEN ACCESS}




\section{FPGA based Gate Signal Generator for Three-level Neutral Point Clamped Inverters}

\author{
Md Rishad Ahmed \\ School of Electrical and Electronic Engineering, \\ Power Conversion Group, The University of Manchester \\ Manchester, United Kingdom. \\ md.rishad.ahmed@postgrad.manchester.ac.uk
}

\author{
Daniel J. Rogers \\ Institute of Energy, School of Engineering, \\ Cardiff University \\ Cardiff, United Kingdom. \\ RogersDJ@cardiff.ac.uk
}

\begin{abstract}
The gate signals in a commercial three-phase twolevel induction motor drive are translated to operate a threephase three-level neutral point clamped (NPC) inverter. An FPGA is used to demodulate the two-level gate signals and then to generate NPC gate drive signals by re-modulation. A sine PWM modulation strategy with in-phase disposition of carriers is used to generate NPC gate drive signals. The modulation strategy is simulated first and then implemented using an Altera FPGA. The close match between the simulation and experimental results proves the concept and demonstrates the accuracy of this unique modulation technique.
\end{abstract}

Keywords - NPC inverter; Modulation strategy; sine PWM; VHDL code; FPGA

\section{INTRODUCTION}

In any $\mathrm{AC}$ motor drive system, harmonics in the applied voltage cause losses and pulsating torques in the motor. The main reason for the development of pulse width modulation (PWM) technique for the motor-drive inverter was to reduce these harmonics and to ensure better control of the fundamental voltage. Again, three level inverters were developed to further reduce harmonics and consequently to increase the efficiency of the motor drive system. [1]

Compared to the two-level inverter a conventional threelevel neutral point clamped (NPC) inverter features two additional active switches, two extra isolated gate drivers, and four extra diodes per phase leg (Fig. 1(a) and 1(b)). In case of three-level T-type neutral point clamped inverter (TNPC), a total of four active switches and four diodes are required per phase (Fig. 1(c)). Both NPC inverters have the advantage of better controllability of phase currents and DC link voltage, lower output current total harmonic distortion and therefore smaller passive components, higher efficiency at increased switching frequency (considering similar modulation technique), and lower voltage stress on the switching components (only for NPC inverter) [2, 3].

There are many PWM modulation techniques for both twolevel inverter and three-level NPC inverter. For both inverters popular PWM techniques are sine-triangle PWM, space vector PWM, PWM with third harmonic injection, programmed PWM with selective harmonic elimination and current-regulated PWM from hysteresis control $[4,5]$. In both cases the simplest form of PWM generation technique is sine-triangular PWM

This work was conducted at Cardiff University under a research project funded by Control Techniques Emerson Industrial Automation. where sinusoidal control signals are compared with the triangular carrier signal(s) to generate gate pulses for the power switches.

Fig. 2(a) and 2(b) respectively show the simplified inputs and actual PWM inputs to the gate drivers of four switches (T1-T4) in a phase leg of a NPC or TNPC inverter circuit shown in Fig. 1(a) and 1(b). Fig. 2 also shows the respective hypothetical phase to neutral voltage output, $\mathrm{u}(\mathrm{t})$. The auxiliary transistors $(\mathrm{T} 2, \mathrm{~T} 3)$ are driven with complementary gate signals to the main transistors $(\mathrm{T} 1, \mathrm{~T} 4)$. When the upper two switches $(\mathrm{T} 1, \mathrm{~T} 2)$ are on, the output voltage is equal to $+\mathrm{DC}$, when the middle two switches (T2,T3) are on, the output voltage is zero, and when the bottom two switches $(\mathrm{T} 3, \mathrm{~T} 4)$ are on, the output voltage is equal to $-\mathrm{DC}$.
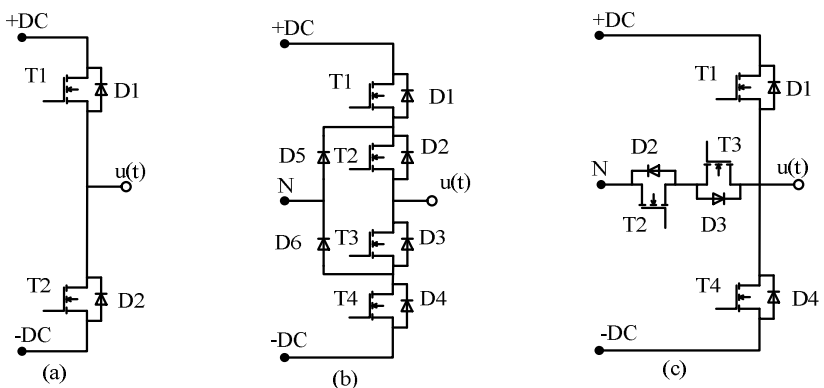

Fig. 1. Phase leg of a (a) 2L inverter, (b) three-level NPC inverter and (c) threelevel TNPC inverter

In this paper an FPGA based implementation of sine-triangular PWM modulation technique for three-level NPC inverter is presented. The uniqueness of the proposed technique is the derivation of the sinusoidal control signals directly from the gate signals of a commercial three-phase bridge (3PB) (twolevel) converter. The two-level PWM gate drive waveform is demodulated and then re-modulated into a three-level PWM gate drive waveform. An example of the useful application of this technique is when investigating how an existing commercial two-level motor drive product would perform with an alternative three-level power output stage. In this case, it is not necessary to redesign an existing and proven Application Specific Integrated Circuit (ASIC) solution from the original product. In addition, if the existing ASIC lacks sufficient PWM output hardware, the cost associated with migrating this into a new ASIC is also avoided. This technique can dramatically reduce development time and is particularly useful in the early 
prototyping an experimentation phase of a design when the advantages of a three-level output stage are under investigation. Although the technique requires the addition of an FPGA device to perform the de- and re-modulation, it could potentially be used in a final design to extend an existing product family whilst keeping common DSP hardware and avoiding a major redesign and qualification process.

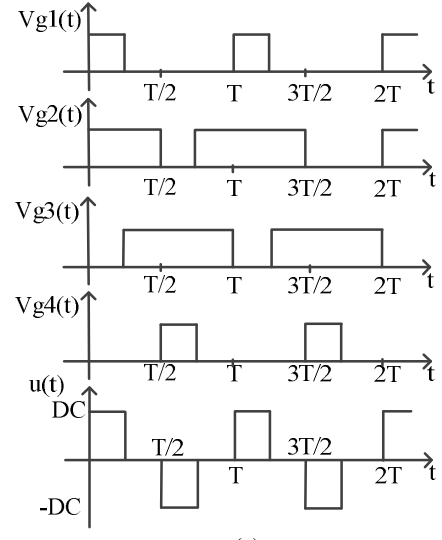

(a)

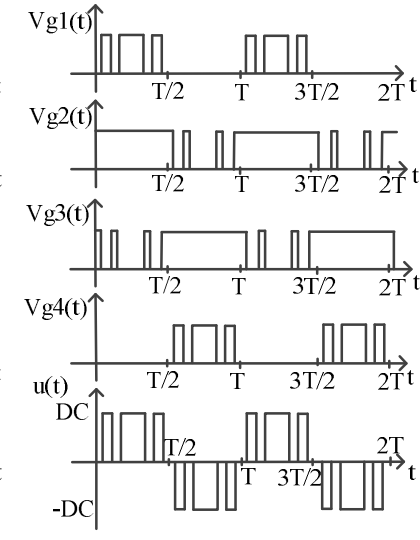

(b)
Fig. 2. Hypothetical gate driver signals and output phase voltage of NPC or TNPC inverter (a) simplified signals and (b) PWM signals

\section{MOdULATION TECHNIQUES FOR THREE-LEVEL NPC INVERTER}

Although there are many strategies for generating gate signals for NPC inverters most of them are extension of either sinusoidal PWM technique or space vector PWM technique or a hybrid technique between them. A brief description of the common modulation techniques from literature is given in this section.

\section{A. Standard Sinusiodal PWM Techniques}

Standard Sinusoidal PWM techniques for NPC inverters can be categorized according to the different types of carrier signals. Usually in three-level NPC inverters two triangular carrier signals are required for sine PWM modulation for each phase. These two carrier signals can be phase shifted or voltage shifted or both phase and voltage shifted. They are compared with a sinusoidal modulating waveform to generate the gate pulses for the semiconductor switches in each phase. The most common sinusoidal PWM techniques for NPC inverters are inphase disposition method and phase-opposition disposition method $[6,7]$.

Fig. 3(a) and 3(b) show the two sine-PWM modulation strategies for three-level NPC or TNPC inverters. In both cases, the frequency of the carrier signals $\left(f_{c}\right)$ determine the switching frequency of the output phase voltages and the frequency of the sinusoidal modulating wave $\left(f_{m}\right)$ determines the fundamental frequency of the output voltages and currents. Also in both cases, the sampling is a natural sampling and the output phase voltage spectrum consists of harmonics at the frequencies, $f_{m}$ (fundamental frequency), $f_{c}$ (switching frequency), $m_{f} f_{c}$ (switching harmonics' frequencies) and $m_{f} f_{c} \pm$ $m_{f} f_{m}$ (side-band harmonics frequencies); where $m_{f}$, the frequency modulation index equals to the ratio between the carrier frequency and the modulating frequency, $f_{c} / f_{m}$. The amplitude modulation index, $m_{a}$ determines the peak of the fundamental component of output phase voltage, $V_{u \_ \text {peak }}$ as shown in equation (1) for linear modulation.

$$
V_{u_{-} \text {peak }}=\frac{m_{a} V_{D C}}{2}
$$

where, $V_{D C}$ is the total DC link voltage and

$$
m_{a}=\frac{A_{m}}{A_{c}}
$$

Here, $A_{m}$ is the peak value of the modulating waveform and $A_{c}$ is the peak value of the carrier waveforms. For linear modulation, $A_{m} \leq A_{c}$.

The PWM gate signals shown in Fig. 2 (b) can be found from the comparison between the modulating and carrier signals shown in Fig. 3. For example, when the modulating signal is greater than the positive carrier signal in Fig. 3(a), then the corresponding semiconductor switch is turned on i.e. $\mathrm{V}_{\mathrm{g} 1}$ is positive. Otherwise the semiconductor switch is turned off i.e. $V_{g 1}$ is zero. Similarly, the negative carrier determines $\mathrm{V}_{\mathrm{g} 2}$. $\mathrm{V}_{\mathrm{g} 3}$ and $\mathrm{V}_{\mathrm{g} 4}$ are found by taking the complementary signals of $\mathrm{V}_{\mathrm{g} 1}$ and $\mathrm{V}_{\mathrm{g} 2}$, respectively. Sometimes, zero sequence voltages are added to the modulating signal to reduce switching losses and to gain better control of the neutral point voltage [8].

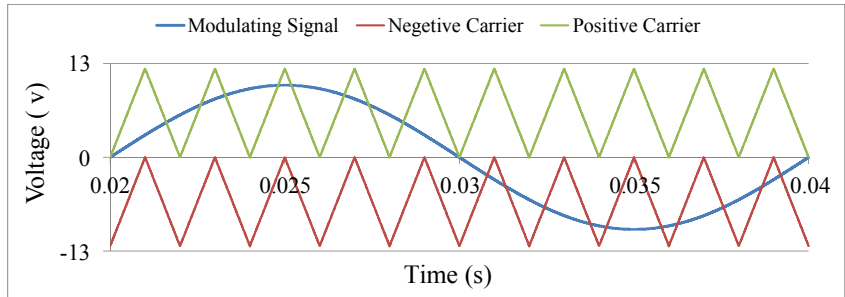

(a)

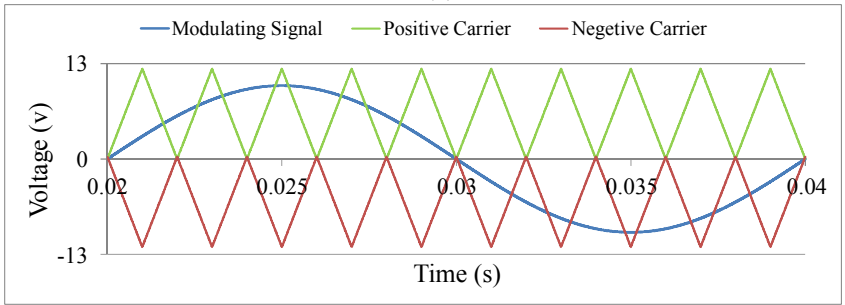

(b)

Fig. 3. Sine PWM strategies for NPC or TNPC inverter (a) in-phase disposition of carriers and (b) phase-opposition disposition of carriers

\section{B. Space Vector PWM Techniques}

As shown in Fig. 2 each output phase voltage of the NPC inverter depends on the switching state of any two phase-leg switches. Therefore, there are three types of switching states per phase and in total there are 27 switching states for the three phase inverter [7,9] If the three switching states corresponding to the DC, 0 and -DC levels are denoted as P, G and N, the 27 switching states can be shown in a space vector diagram as in Fig. 4. Based on the magnitude and the angle of the output voltage phasor (a space vector voltage), four groups of the switching states are selected from the space vector diagram of Fig. 4. Different optimization techniques such as minimum commutations, commutations only between adjacent states, 
easy transitions etc. are used to optimize the switching sequence of this modulation technique [7,9].

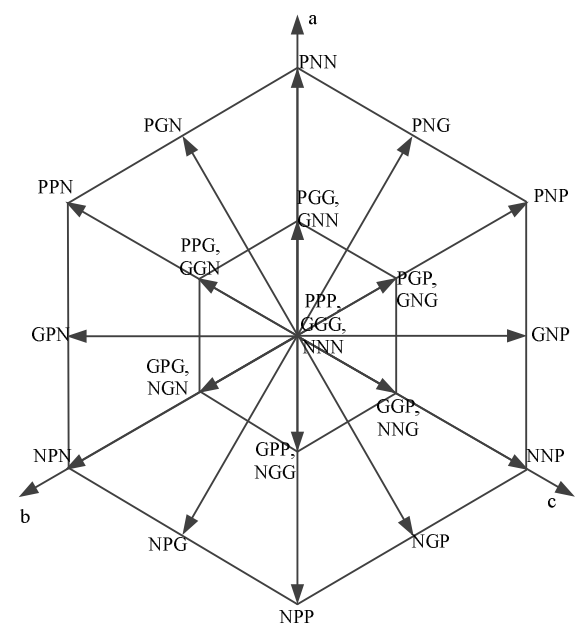

Fig. 4. Space vector diagram of NPC or TNPC inverter output voltage

\section{Double Signal PWM Techniques}

Two modulating signals are used per phase to generate the gate pulses in double signal PWM techniques. The simplest of these techniques uses two sinusoidal modulating waves, one positive and one negative and one triangular wave to generate the gate pulses for a phase leg (dipolar modulation) [5]. In [10], two modified modulation signals were derived using a zero sequence voltage obtained from space-vector modulation patterns, which were then compared with two carrier signals to generate the gate pulses. Low frequency voltage oscillation of the neutral point was reduced by this method at the expense of increased switching losses compared to the sine PWM or space vector PWM techniques.

\section{Other Hybrid Modulation Techniques}

Several other hybrid modulation techniques were proposed for NPC inverters in the previous literatures. A hybrid modulation strategy combining the zero sequence voltage based double signal PWM and sine PWM is proposed in [11], where the two modulating signals are further modified using a separate controlling parameter. This strategy gives an optimum performance in voltage sharing of the DC-link capacitors under all power factor operations at the expense of slightly higher switching loss. A DSP based single carrier modulation strategy is proposed in [12], where gate signals between the three phases were cross-coupled to get the neutral point voltage balance.

\section{CONFIGURATION OF THE SYSTEM}

A three-level NPC inverter's modulator based on the sine PWM modulation was designed. In-phase disposition of carriers were used as the sine PWM modulation technique because of its better harmonic performance compared to others [6]. The three control signals for the sine PWM modulation had to be derived from an Emersion Control Techniques Unidrive SP0401. It is a commercial $400 \mathrm{~V}$ rated motor drive based on a three-phase bridge (3PB) converter which can run in both open loop and closed loop mode. Space vector PWM with third harmonic injection is the modulation strategy for the Unidrives
[13]. The gate driving circuit of the Unidrive SP0401 was modified to access the three gate signals of either upper-leg power devices or lower-leg power devices of the 3PB converter. Then, the three gate signals were demodulated to get the three control signals for sine PWM modulation of threelevel NPC inverter. An FPGA was used for the demodulation and also for the further sine PWM modulation of the NPC inverter.

\section{SimULATION RESULTS}

Both NPC and TNPC inverters were simulated in National Instrument Multisim Software considering 800V DC link. All the switches were considered ideal and independently operated and no parasitic was considered in the circuits. The parameters of a $4 \mathrm{~kW}$ induction machine were used to simulate a fixed load, considering its fixed speed operation. Therefore, the frequency of phase to neutral voltage was $50 \mathrm{~Hz}$.

Fig. 5 depicts the gate signal generation strategy using sine PWM modulation technique. Although, here it is shown for only one phase-leg, the arrangement for rest of the two phaselegs was exactly same except for the control voltages, which would be $120^{\circ}$ phase shifted from each other. In the upper two comparators, the $50 \mathrm{~Hz}$ sinusoidal control signal was compared with two $3 \mathrm{kHz}$ triangular carrier signals. Both triangular signals (V3 and V4) had only positive values, but they were $1 \mu \mathrm{s}$ delayed from each other to ensure $1 \mu \mathrm{s}$ dead-time between the complementary gate signals. The output of these comparators produced the gate signals for the transistor, T1 and its complementary pair transistor, T3 (Fig. 1). Similarly, gate signals for the transistor T2 and its complementary pair, T4 were generated by comparing the same control signal with two triangular signals with only negative values (V1 and V2). Essentially, V1 and V2 were in phase with V3 and V4, respectively, but voltage shifted by an amount equal to the peak value of V3 and V4. The ratio between the peak values of control signal and carrier signal gives the modulation index, $m_{a}=0.813$. This modulation index was calculated from (1) to get the $230 \mathrm{~V}$ RMS phase to neutral voltage, $V_{u}$.

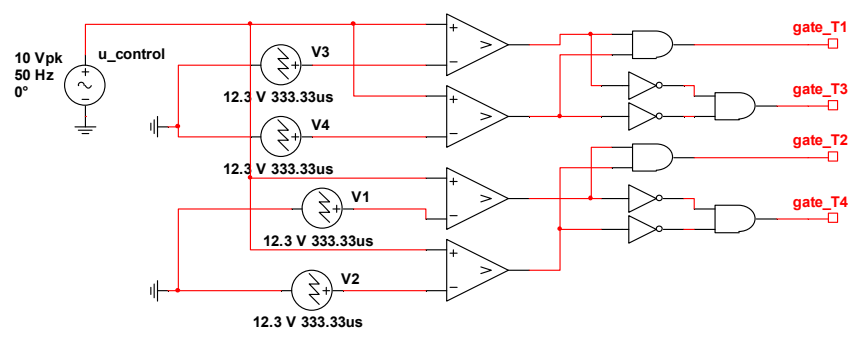

Fig. 5. Implementation of sine PWM modulation in one phase-leg of the NPC and TNPC inverters

The generated gate signals along with the control signal and carrier signals from the simulation are shown in Fig. 6. The generated gate signals have coherent shapes of the theoretical gate signals shown in Fig. 2(b).

\section{FPGA IMPLEMENTATION}

The sine PWM modulation strategy for the NPC inverter was implemented using an Altera DE0-Nano development board. The control signals for the modulator were found by 

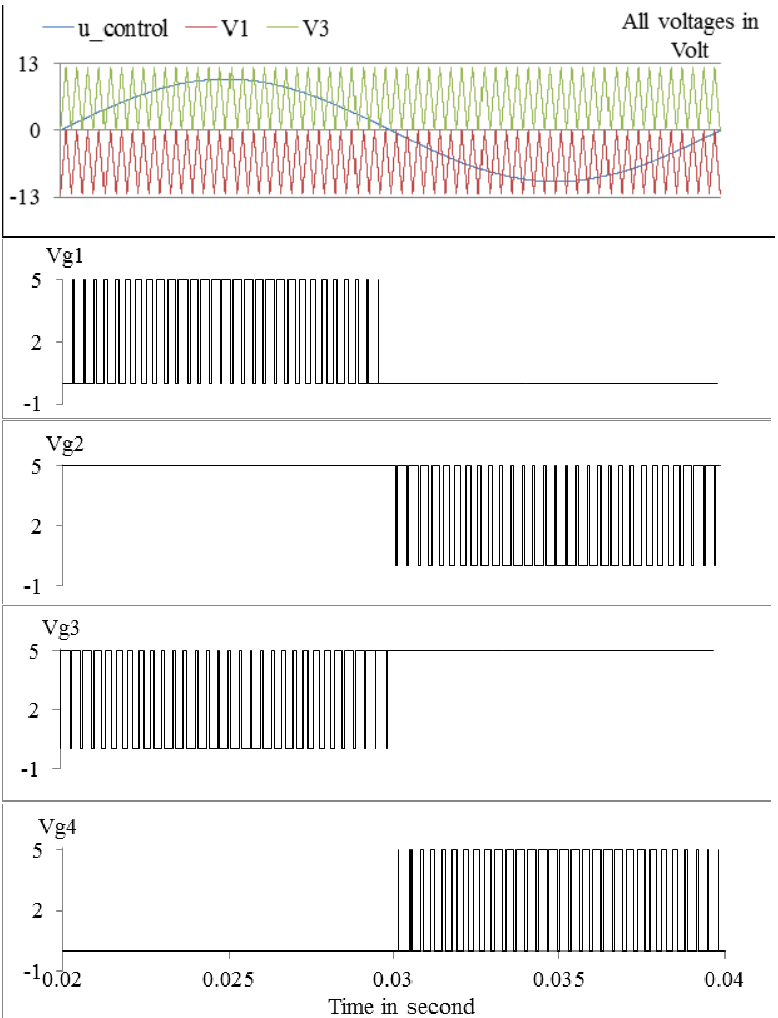

Fig 6. NPC inverter modulator's control signal, carrier signals, and gate driver inputs of a phase-leg (simulation results)

demodulating the gate signals of a three phase bridge (3PB) inverter of Unidrive SP0401. The block diagram of this FPGA implementation for a phase-leg of the NPC inverter is shown in the Fig. 7. At first, from the 3PB gate driver a PWM gate signal is taken as an input to the FPGA. The "control signal generator' block demodulates the input PWM to generate a sinusoidal control signal $\left(D_{a}\right)$ by making two measurements using a high speed internal clock $(10 \mathrm{MHz})$ :

1. The time between a rising edge and the subsequent falling edge of the input PWM signal, $t_{H}$

2. The time between two consecutive rising edges of the input PWM signal, $T_{P W M}$

From these two quantities, $D_{a}$ may be calculated as, $D_{a}=$ $t_{H} / T_{P W M}$ and is updated on every rising edge of the input PWM signal.

Assuming the 3PB inverter is operating with a modulation index below one i.e. in linear modulation range, the control signal, $D_{a}$ will vary within a range of 0 to 1 . Therefore, the maximum $\mathrm{AC}$ amplitude of $D_{a}$ can be 0.5 . $T_{P W M}$ acts as an input to the 'Carrier signals generator' block which fixes the period of the two generated triangular carrier signals, the output of this block. The amplitude of both of the triangular waves has to be 0.5 so that the modulation index of the NPC PWM signal can change with respect to the change of modulation index in 3PB inverter. The 'comparator' block then compares the control signal with the two triangular waves to generate the PWM gate-driver signals for the upper two switches of the phase leg. The 'dead time' block generates the complementary gate signals for the lower two switches with a specific dead time. Finally, three sets of blocks shown in Fig. 7 were required for three phases.

The FPGA was programed using Quartus II software using VHDL programming language. The sampling of the signals was done with a $10 \mathrm{MHz}$ clock derived from the $50 \mathrm{MHz}$ oscillator of the DE0-Nano board.

\section{A. Control signal generator block}

This block continuously tries to detect the rising edges and falling edges of the input PWM signal by comparing an existing input with the immediate last input in every clock pulse. At every rising edge of the input it initiates a counter, which determines the width of the pulse at the falling edge of the input. The same counter determines the period of the input PWM, $T_{P W M}$ at the next rising edge. Then the duty ratios are calculated by dividing the pulse width value with the period value. However, this division will create a fixed point number ranging from 0 to 1 . Therefore, to eliminate the need for a fixed point calculation, each duty ratio is multiplied by a 17 bit number $65536\left(2^{\wedge} 16\right)$. The duty ratio of the 3 PB gate signal changes in a sinusoidal manner [14] according to equation (3).

$$
D_{a}(t)=\frac{1}{2}\left[1+m_{a} \sin \left(2 \pi f_{m} t\right)\right]
$$

Here $m_{a}$ is the modulation index and $f_{m}$ is the frequency of the control signal. During the steady state operation of induction machine connecting to the drive, $m_{a}$ will be 0.813 (Section IV). So, $D_{a}(t)$ will be changing from 0.0935 to 0.9065 (Fig. 7). The 17 bit multiplier, 65536 will increase the accuracy between the calculated duty ratios.

\section{B. Carrier signals generator block}

The basic logic behind this block for generating triangular wave is as follows: during half of the PWM period, $T_{P W M}$ the amplitude of one triangular wave is incremented from 0.5 to 1 and the other half of the period the amplitude is decremented from 1 to 0.5 . The other voltage shifted triangular wave is found by vertically shifting the first triangular wave by 0.5 . Because the control signal is multiplied by 65536 , so the triangular waves are also weighted by the same number to ensure clarity in further calculations between them.

\section{Comparator block}

The control signal is compared with the two triangular waves to generate the gate driver signals for the upper two switches using the logic explained in Section II.

\section{Dead time block}

The dead time blocks produce the final NPC inverter's gate driver signals with a specific dead time between the complementary signals. There is also an enable input to this block through which all the outputs can be forced to zero.

\section{E. Input and output safety blocks}

As the input PWM signals to the FPGA are not synchronised with the FPGA clock signal, therefore, there is a possibility that the input signal transition can fall near to a clock edge, which can violate any register's timing requirements causing metastability problems. One way to mitigate the metastability problem is to add some delay to the 


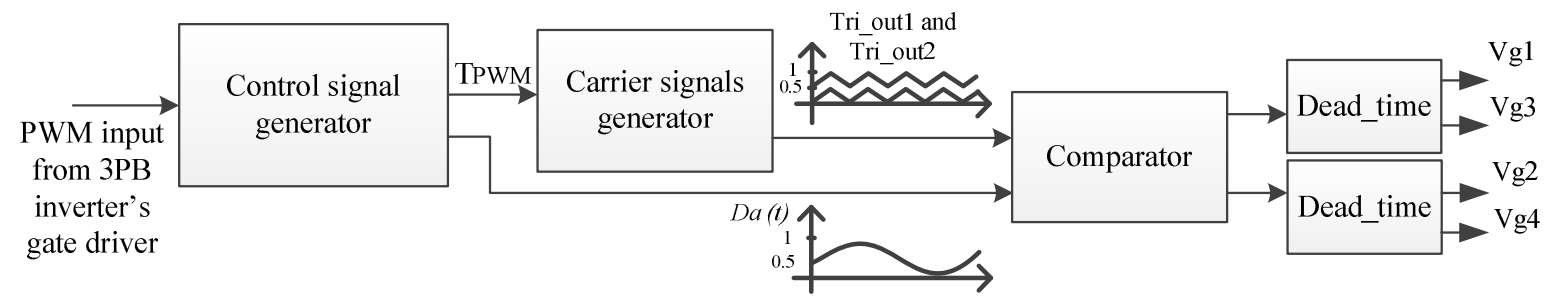

Fig. 7. FPGA block diagram to produce gate driver signals for one phase-leg of a NPC inverter

input PWM by adding extra register stages as the probability of metastability decreases exponentially with respect to the propagation delay [15]. For this reason 3PB PWM signals went through some D-flip-flops before they enter the 'Control signal generator' block.

Again, output NPC PWM gate driver signals could be turned on or turned off by three DIP switches on the DE0Nano board. Another safety block was also included to check input signals before turning on the output. I $\mathrm{n}$ total $27 \%$ of the total logic elements and 588 dedicated logic registers of the Cyclone IV FPGA were used for the design.

\section{EXPERIMENTAL RESULTS}

The programed FPGA was tested by using a TGi TG5011A function generator and a modified Control Techniques Unidrive SP0401. With the function generator only single phase-leg NPC gate driver signals could be observed because of its single channel output. With the Unidrive all the twelve gate driver signals for an NPC inverter were observed.

\section{A. Testing the modulator with a function generator}

A PWM signal was generated with the function generator by comparing a $50 \mathrm{~Hz}$ control signal with a $3 \mathrm{kHz}$ switching signal. It was put as an input to the designed modulator and four gate driver signals were found for a phase-leg of an NPC inverter. Input and output signals are shown in Fig. 8.

The results showed good coherence with the theory and simulation. The generated PWM signals also showed close to $20 \mathrm{~ms}$ fundamental period as shown in Fig. 8, which corresponded to the $50 \mathrm{~Hz}$ control signal. The switching frequency of the input PWM and the frequency of the control signal were changed to different values and the output gate driver signals were observed to validate the modulator's performance at different operating conditions.

\section{B. Testing the modulator with a Unidrive}

A modified Unidrive SP0401 was used to get isolated six 3PB inverter gate signals from it using its low voltage DC operation mode. The three gate signals to the lower phase-leg switches of the 3PB inverter were used as the inputs of the FPGA modulator. A resistive divider was used to interface the Unidrive with the DE0-Nano board. It converted the 24V logic signals from the Unidrive to $3.3 \mathrm{~V}$ logic signals, a compatible level for the FPGA input pins.

The input DC link voltage of the Unidrive was fixed to $48 \mathrm{~V}$ for its low voltage DC operation mode. Therefore, its maximum rotational frequency setting had to be fixed to 105 $\mathrm{rpm}$ to ensure the gate signals were under-modulated (the open loop $\mathrm{V} / \mathrm{f}$ profile could not be changed in the Unidrive).
This corresponded to an output voltage frequency of $3.5 \mathrm{~Hz}$. The output NPC inverter's gate driver signals were observed for different switching frequencies $(3,4,6,8,12$ and $16 \mathrm{kHz})$.

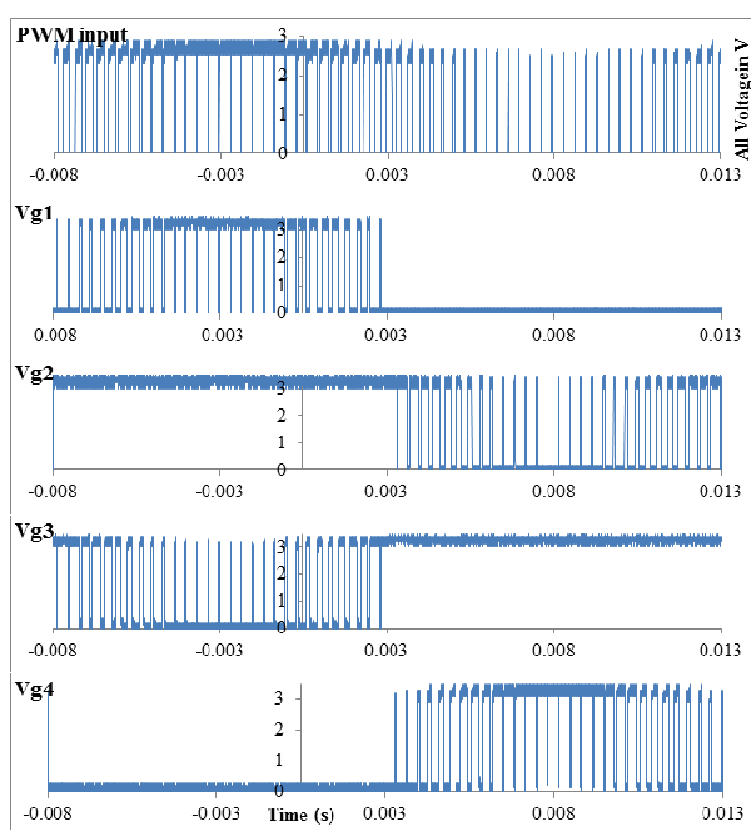

Fig. 8. Modulator input from a function generator and the NPC inverter gate driving signal outputs ( $3 \mathrm{kHz}$ switching frequency)

The gate driver signals for the upper leg switches are shown in Fig. 9 and Fig. 10 for the switching frequencies of $3 \mathrm{kHz}$ and $12 \mathrm{kHz}$, respectively. Here $\mathrm{Vg} 11, \mathrm{Vg} 12, \mathrm{Vg} 21$, $\mathrm{Vg} 22, \mathrm{Vg} 31$, and $\mathrm{Vg} 32$ correspond to the gate driver input signals for the upper-leg switches of a three phase NPC inverter. From both figures it is clear that all the produced gate driver signals closely match the theory and simulation results. However, as the input PWMs from the Unidrive was not as clean as the PWM from the signal generator, most of the gate signals had spearing pulses at around -0.004 second in Fig. 10.

It is believed that an improved signal conditioning circuit inserted between the Unidrive and the FPGA would eliminate this problem (for these tests only a crude potential divider circuit was used to translate the $24 \mathrm{~V}$ drive signals to $3.3 \mathrm{~V})$. It is likely that a dedicated level-shifting device would improve matters considerably. Alternatively, a direct tap from the Unidrive ASIC PWM outputs (which are likely $3.3 \mathrm{~V}$ or $5 \mathrm{~V}$ logic signals) could be used as input to the FPGA instead of the gate signals. This would have the additional advantage of removing any pulse-length distortion introduced by the gate drive circuitry, but may bypass any additional protection logic external to the ASIC. 


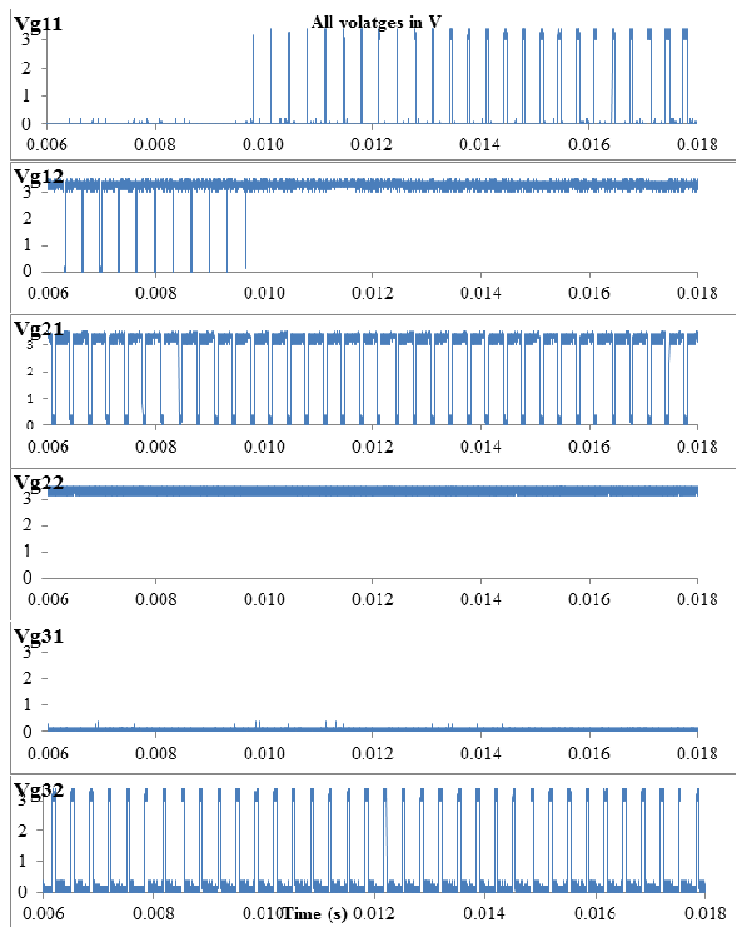

Fig. 9. NPC inverter gate driver signals for upper-leg switches ( $3 \mathrm{kHz}$ switching frequency)
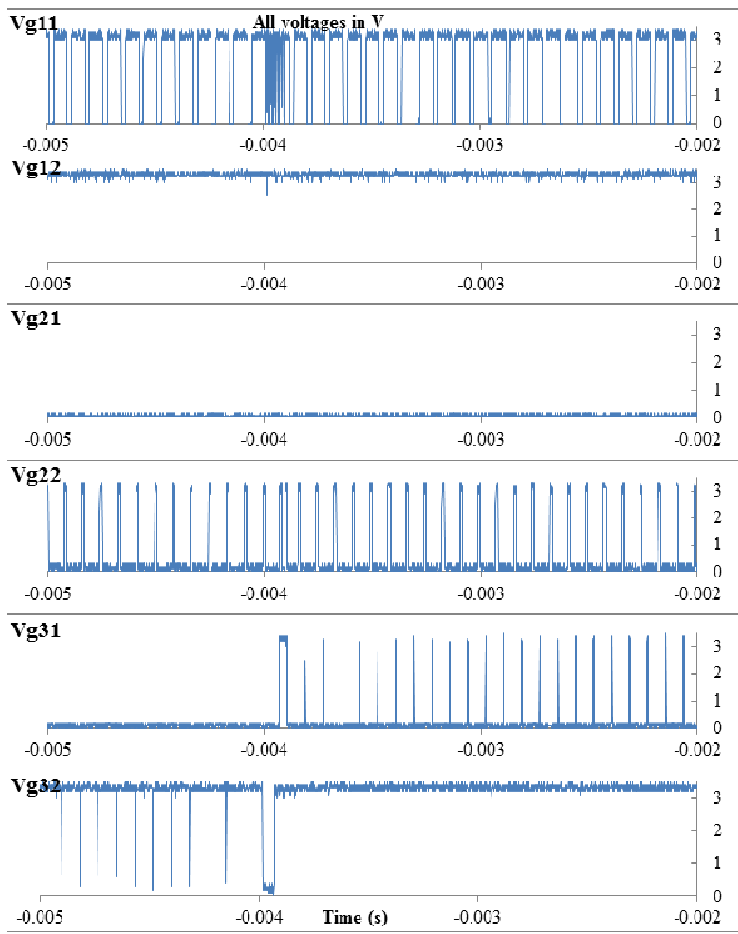

Fig. 10. NPC inverter gate driver signals for upper-leg switches (12 kHz switching frequency)

\section{CONCLUSIONS}

The design procedure of a sine PWM modulator for a NPC or TNPC inverter has been presented in this paper. The practical implementation was done using an FPGA, where the input control signals were derived from PWM gate signals of a $3 \mathrm{~PB}$ inverter. At first, the modulation technique was verified by simulating the NPC and TNPC inverters in National Instrument Multisim software. Then VHDL code was prepared for different blocks of the modulator. Two safety features were included at the input and at the output to ensure its proper operation. The gate driver signals generated from the FPGA matched closely with the simulation results and theoretical predictions.

The study concluded with the production of proof-ofconcept hardware demonstrating that the existing Unidrive design can be modified to extract the required PWM signals and that these signals can be practically re-modulated to drive an NPC output stage. One application of this modulation technique would be comparing the performance of an identically rated two-level 3PB inverter with a threelevel NPC or TNPC inverter where both of them would use the same control loop.

\section{ACKNOWLEDGEMENTS}

The authors would like to thank Dr. Richard Gibson and Mr. Frank Heerdt from Control Techniques Emerson Industrial Automation for providing the modified Unidrive and for their valuable advice during the project.

\section{REFERENCES}

[1] A. Nabae, I. Takahashi, and H. Akagi, "A New Neutral-Point-Clamped PWM Inverter," Industry Applications, IEEE Transactions on, vol. IA-17, no. 5, pp. 518-523, 1981.

[2] T. B. Soeiro, and J. W. Kolar, "Novel 3-level Hybrid Neutral-Point-Clamped Converter," 37th Annual Conference on IEEE Industrial Electronics Society, pp. 4457-4462, 7-10 Nov. 2011.

[3] Semikron, "Application Note AN-11001: 3L NPC \& TNPC Topology," [online]

[4] B. K. Bose, Power electronics and motor drives: advances and trends: Academic press, 2010

[5] L. Bor-Ren, "Analysis and implementation of a three-level PWM rectifier/inverter," Aerospace and Electronic Systems, IEEE Transactions on, vol. 36, no. 3, pp. 948-956, 2000.

[6] R. K. Behera, T. V. Dixit, and S. P. Das, "Analysis of Experimental Investigation of Various Carrier-based Modulation Schemes for Three Level Neutral Point Clamped Inverter-fed Induction Motor Drive," International Conference on Power Electronics, Drives and Energy Systems, 2006. PEDES '06. pp. 1-6, 12-15 Dec. 2006.

[7] A. Bellini, and S. Bifaretti, "Comparison between sinusoidal PWM and Space Vector Modulation Techniques for NPC inverters," Power Tech, 2005 IEEE Russia, pp. 1-7, 27-30 June 2005.

[8] I. López, S. Ceballos, J. Andreu et al., "Review of Modulation Algorithms for Neutral-Point-Clamped Multilevel Converter." [online]

[9] S. Jae-Hyeong, C. Chang-Ho, and H. Dong-seok, "A new simplified spacevector PWM method for three-level inverters," Applied Power Electronics Conference and Exposition, 1999. APEC '99. Fourteenth Annual, vol. 1, pp. 515-520 vol.1, 14-18 Mar 1999, 1999.

[10] J. Pou, J. Zaragoza, P. Rodriguez et al., "Fast-Processing Modulation Strategy for the Neutral-Point-Clamped Converter With Total Elimination of Low-Frequency Voltage Oscillations in the Neutral Point," Industrial Electronics, IEEE Transactions on, vol. 54, no. 4, pp. 2288-2294, 2007.

[11] J. Zaragoza, J. Pou, S. Ceballos et al., "A Comprehensive Study of a Hybrid Modulation Technique for the Neutral-Point-Clamped Converter," Industrial Electronics, IEEE Transactions on, vol. 56, no. 2, pp. 294-304, 2009.

[12] G. Xiaoqiang, M. C. Cavalcanti, A. M. Farias et al., "Single-Carrier Modulation for Neutral-Point-Clamped Inverters in Three-Phase Transformerless Photovoltaic Systems," Power Electronics, IEEE Transactions on, vol. 28, no. 6, pp. 2635-2637, 2013.

[13] Control_Techniques, "Unidrive SP Advanced User Guide," [online]

[14] K. Berringer, J. Marvin, and P. Perruchoud, "Semiconductor power losses in AC inverters," Thirtieth IAS Annual Meeting, IAS '95., vol. 1, pp. 882-888 vol.1, 8-12 Oct 1995.

[15] Altera, "White Paper: Understanding Metastability in FPGAs " [online] 